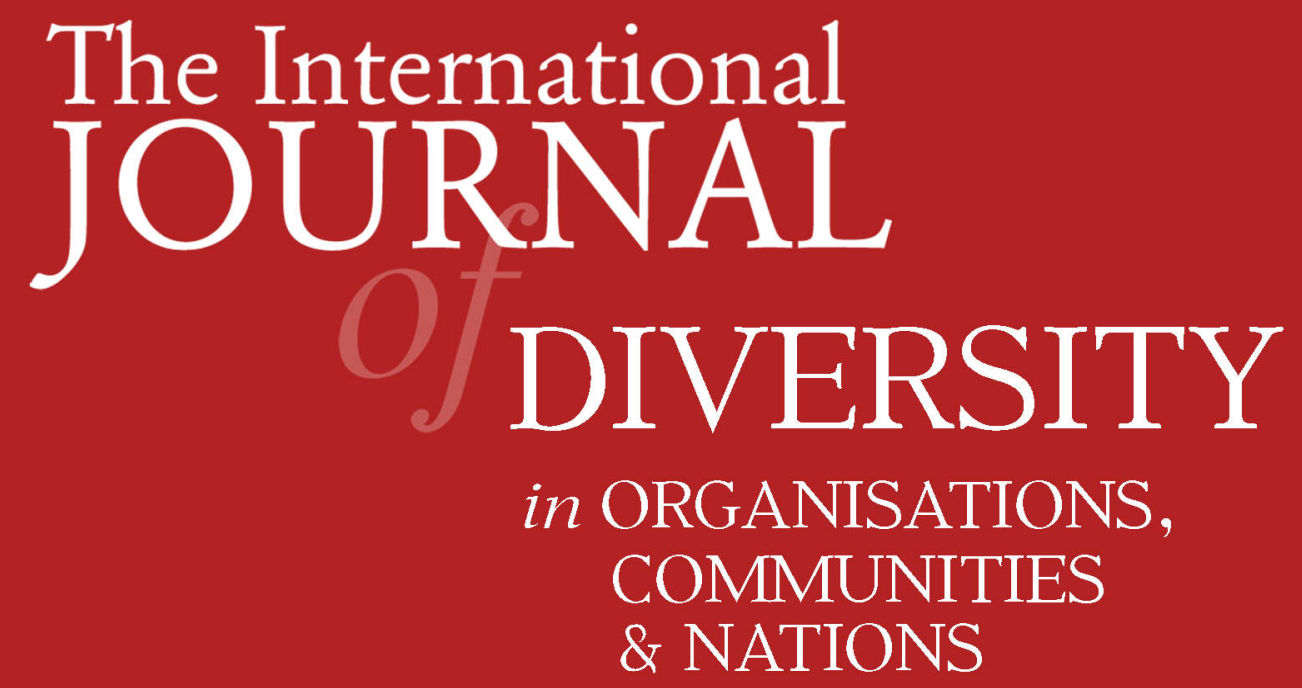

Environmental Justice

Pamela J. Lomelino

VOLUME 6 


\section{INTERNATIONAL JOURNAL OF DIVERSITY IN ORGANISATIONS, COMMUNITIES AND NATIONS}

http://www.Diversity-Journal.com

First published in 2006 in Melbourne, Australia by Common Ground Publishing Pty Ltd www.CommonGroundPublishing.com.

(C) 2006 (this paper), the author(s)

(C) 2006 (selection and editorial matter) Common Ground

Authors are responsible for the accuracy of citations, quotations, diagrams, tables and maps.

All rights reserved. Apart from fair use for the purposes of study, research, criticism or review as permitted under the Copyright Act (Australia), no part of this work may be reproduced without written permission from the publisher. For permissions and other inquiries, please contact <cg-support@ commongroundpublishing.com>.

ISSN: 1447-9532 (print), 1447-9583 (online)

Publisher Site: http://www.Diversity-Journal.com

The INTERNATIONAL JOURNAL OF DIVERSITY IN ORGANISATIONS, COMMUNITIES AND NATIONS is a peer refereed journal. Full papers submitted for publication are refereed by Associate Editors through anonymous referee processes.

Typeset in Common Ground Markup Language using CGCreator multichannel typesetting system http://www.CommonGroundSoftware.com. 


\title{
Environmental Justice
}

\author{
A Proposal for Addressing Diversity in Bioprospecting \\ Pamela J. Lomelino, University of Colorado, United States of America
}

\begin{abstract}
Recently, there has been an insurgence of corporations that bioprospect in Third World countries (going into these areas in hopes of utilizing traditional knowledge about local natural resources so as to eventually develop a synthetic alternative that they can then market). Although this type of bioprospecting does not encounter the problem of depleting environmental resources, other problems arise. Two primary problems are: (1) determining who has legal ownership of these resources, and (2) who should share in the profits that were derived, in part, from these resources. Despite the attention that these problems have received, there has been little attention focused on the issue that I believe underlies these problems ${ }^{\wedge}$ the differing views of nature between corporations (who consider nature to be an individually owned resource) and Third World communities (many of whom consider nature to be a communally owned resource). In this paper, I will present what I believe is an additional useful tool for policy makers in resolving the current problems regarding bioprospecting in Third World countries. The tool I have in mind is a set of method components that can be used as guidelines as well as a test for inclusiveness. To arrive at these components, I will look to James D. Proctor's methodological proposal for resolving conflicts between those with differing views of nature. Because he presents this methodology in a limited context (as a means of resolving the Ancient Forest debate), I will clarify and expand his methodology so as to arrive at a set of methods that I believe can be helpful in arriving at a fair global policy regarding bioprospecting in Third World countries.
\end{abstract}

Keywords: Global Policy, Bioprospecting in Third World Countries

W

ITH SIXTY TO seventy percent of the world's biodiversity located in seventeen Third World countries ${ }^{1}$, bioprospecting (prospecting for useful applications, processes or products in nature $)^{2}$ has been on the rise. Bioprospecting often takes one of two possible forms. Bioharvesting occurs when corporations directly harvest environmental resources, marketing them as products for commercial gain. Fortunately, the Convention on Biodiversity (CBD) makes it illegal for anyone to deplete natural resources to the extent that it negatively impacts biodiversity. ${ }^{3}$ Consequently, the second form of bioprospecting has received the most attention -- bioprospecting that occurs when scientists or corporations take a sample environmental resource, test it for beneficial applications, and attempt to reproduce this benefit in the laboratory so as to eventually arrive at a marketable product. Although this type of bioprospecting does not encounter the problem of depleting environmental resources, other problems arise. In searching for beneficial natural resources, scientists and corporations oftentimes narrow their search within this extremely biodiverse area of the globe by relying on communities' traditional knowledge of their natural resources. When corporations, in turn, are able to produce a marketable and profitable product, concerns over inequitable benefit sharing arise - namely, the concern that corporations are not adequately compensating (or giving no compensation at all to) Third World communities. Those within the environmental and philosophical communities have come to refer to this as "biopiracy". Moreover, this concern over biopiracy is justified given the current statistics on corporations that have allegedly pirated indigenous knowledge. For example, "the US-based Edmonds Institute recently published a report listing more than 30 examples of western medical, horticultural and cosmetic products it alleged had been 'pirated' from Africa (KenyaLondon News; August 28, 2006, \16)".

Although there has been much attention directed towards solving these problems (i.e.: Shiva, 2000; Gepts, 2004; Third World Network Biosafety Information Service, 2005), the discussion has been focused on proposed policy changes with regard to: (1) intellectual property rights, and (2) benefit sharing. Despite the apparent importance of these discussions, it

\footnotetext{
${ }^{1}$ Bolivia, Brazil, China, Colombia, Costa Rica, Democratic Republic of Congo, Ecuador, India, Indonesia, Kenya, Madagascar, Malaysia, Mexico, Peru, Philippines, South Africa, and Venezuela. (Megadiverse Countries, 2005, p.1)

${ }^{2}$ Benefit Sharing in the National Parks, p.1.

${ }^{3}$ The Convention on Biological Diversity (CBD; signed in 1992 but not in effect until 1993) sets regulations for bioprospecting worldwide. Included in the $\mathrm{CBD}$ are several Articles that require the conservation of the environment and the protection of biodiversity, thus banning bioprospecting that results in harming the environment. (Common Policy Guidelines, 2000).
}

INTERNATIONAL JOURNAL OF DIVERSITY IN ORGANISATIONS, COMMUNITIES AND NATIONS, VOLUME 6, 2006 http://www.Diversity-Journal.com, ISSN 1447-9532 (print), 1447-9583 (online)

(C) Common Ground, Pamela J. Lomelino, All Rights Reserved, Permissions: cg-support@commongroundpublishing.com 

VOLUME 6

is important to note that there has been little attention focused on striving for an inclusive bioprospecting policy that addresses what I believe is the underlying issue - the differing views of nature between corporations and many Third World communities. ${ }^{4}$ Whereas corporations consider nature to be an independently owned resource, many Third World communities consider it to be communally owned. (It is important to note that, in stating this, I am by no means implying that there is a uniform interpretation of nature that is shared by all Third World communities. Instead, I am focusing on those communities who interpret nature as a communally owned resource.) With these differing views regarding nature, it is understandable that corporations and many Third World communities would disagree as to what property rights are applicable to traditional knowledge and natural resources. In addition, it is this disagreement about ownership that lies at the heart of the disagreement regarding benefit sharing; if community ownership of traditional knowledge or natural resources is not acknowledged then the community is robbed of any possible claim in the eventual benefits derived from these resources.

Given this underlying issue in the current bioprospecting debate (contending views of nature), I believe that it will help policy makers to have a tool specifically directed towards addressing this contention so as to arrive at more equitable benefit sharing policies. The tool I have in mind is a set of method components that can be used as guidelines as well as a test for inclusiveness. To arrive at these components, I will draw on James D. Proctor's methodological proposal for resolving conflicts between those with differing views of nature. Because he presents this methodology in a limited context (as a means of resolving the Ancient Forest debate), I will clarify and expand his discussion so as to arrive at a set of method components. After doing so, I will briefly outline some of the general ways in which these components can be applied to the current bioprospecting debate. Because I have not come across other methodologies directed at resolving the problem of contending views of nature, I am by no means asserting that my proposed methods are the only means by which one can do so. For the time being, however, and given the severity of the problem, I encourage policy makers to consider adopting these methods so as to arrive at fair bioprospecting benefit sharing policies.

\section{Expanding Proctor's Guidelines}

In his article, "Whose Nature? The Contested Terrain of Ancient Forests" (1996), James D. Proctor builds on his discussion of various definitions of nature and their subsequent varying environmental ethics to arrive at his proposed methodological approach for resolving conflicts that arise from these differing views. Despite the fact that he wrote this article several years ago and intended for it to be applicable to the limited context of the Ancient Forest debate, I believe that the methodology he provides is timeless and can be helpful in much broader contexts. Because I am here concerned with Proctor's proposed methodological components and how these can be applied to bioprospecting, I will not address his discussion of the differing views of nature in the Ancient Forest campaign and the resultant contrasting environmental ethics. Instead, I will present and further develop his proposed methodology for resolving conflicts in which there are opposing views of nature prior to applying them to a particular bioprospecting case.

In attempting to bridge the gap between differing environmental ethics with regards to the Ancient Forests, Proctor proposes what he refers to as "some major landmarks to keep in sight (295)". According to Proctor, we should: (1) strive for a realist notion of moral pluralism; (2) take an anthropogenic and not anthropocentric approach; and (3) take into account important relationships with regard to location. In mentioning that these landmarks have to do with process (and not product; 295), it appears that Proctor is presenting us with methodological suggestions. However, it also appears that these are more than mere suggestions, for at the end of his article he refers to the "necessity of moral pluralism; the inevitability of an anthropogenic... approach; and the need to root, but not limit, ethics to place (Italics added; 295)." Thus, in response to the problem of the current contrasting environmental ethics that stem from differing views of nature, it appears that he presents us with three necessary methodological suggestions.

\section{Moral Pluralism}

In presenting his first guideline of striving for a realist moral pluralism, Proctor argues that we should be neither Absolutist nor Relativist; instead, we should strive to be somewhere in the middle. In order to accomplish this middle ground, he asserts that we must "embrace a necessary paradox (290)". On the one hand, we must address the strongly subjective

\footnotetext{
${ }^{4}$ By focusing on the problem of contending views of nature, I am by no means implying that this is the only problem with regards to bioprospecting. Because the current legislation that relates to bioprospecting (the Convention on Biological Diversity [CBD] and the Trade Agreement dealing with Intellectual Property [TRIPs]) gives the negotiating power for benefit sharing to the governments and agencies within the relevant countries, there are important issues with regards to the influence of government, the responsibility of government to its citizens, and the responsibility of global citizens to members of Third World communities. Since I cannot address all of these issues in a paper of this length, it is my hope that others will do so.
} 
aspect present in the Ancient Forest campaign that is comprised of diverse perspectives with regards to how we should treat the environment. At the same time, however, he argues that we must also recognize the objective aspects of the Ancient Forest debate. For example, despite their differing perspectives of 'nature', Proctor points out that both sides of the ancient forest campaign value the forest and its inhabitants and are concerned with the effects of their actions on these.

Although Proctor informs us that we must strive for a realist notion of moral pluralism, he does not expand on how this can be implemented in order to arrive at an inclusive environmental policy (and, with all due respect, this is not his intent). Yet, we can certainly take his suggestion a step further and attempt to formulate a more concrete method component. Keeping in mind his suggestion to embrace the subjective/ objective paradox, it makes sense that we should first locate the subjective and objective elements within a debate. Doing this places us in a position in which we can now take into account the differing subjective perspectives while grounding the discussion in an objective element. The advantage of doing this, I believe, is that it respects and recognizes the importance that differing views of the environment have without getting lost in this diversity (since we are able to utilize the objective element as a starting point for productive discussions of how we should treat the environment or traditional knowledge about the environment).

\section{An Anthropogenic Approach}

The second methodological guideline that Proctor presents is to strike a balance regarding our emphasis on human beings. On one end of the spectrum is the nonanthropocentric environmental ethic - an ethic that asserts that nature's value is intrinsic and does not rely on being instrumentally valuable to human beings. Yet, as Proctor points out, we should reject relying on this extreme ethic because it rules out those who hold an anthropocentric ethic (according to which nature's value rests solely on its instrumental benefit to humankind). At the same time, however, he also argues that we should reject moving to the other side of the spectrum regarding our emphasis on human beings by adopting an anthropocentric approach. Not only does this approach rule out those who hold a nonanthropocentric view, but it also fails to provide any justification for valuing the environment aside from human needs. Instead of adopting either a nonanthropocentric or an anthropocentric ethic, Proctor argues that we should take an anthropogenic approach - one that acknowledges (but is not driven primarily by) human concerns.
Although he does not mention this, it is important to note the following additional benefit of an anthropogenic approach: doing so helps to reinforce our striving for a realist notion of moral pluralism. Recall that while some value the environment from an instrumental standpoint, others value it from a noninstrumental standpoint. By taking into account both the instrumental and noninstrumental values of the environment, an anthropogenic approach supports the first methodological approach of striving for moral pluralism by incorporating these various perspectives with regard to the environment.

\section{Location and Its Relevant Relationships}

Lastly, Proctor argues that we must take location into consideration when attempting to formulate an inclusive environmental policy. As Proctor points out, we must recognize that people's ethics arise from their experiences with nature. Thus, for example, in the Ancient Forest debate, all the experiences of those who have interacted with the Pacific Northwest Forests should be considered. In addition, the experience of the forest itself (its fire history, climate and vegetation changes) must also be taken into account. In taking location into account, however, it is important to note that Proctor warns that we should not be limited to location. In addition to the relationship between the land and the people, we must also consider other relationships that extend beyond the borders of the Ancient Forest.

As with his previous guideline of taking an anthropogenic approach, Proctor again does not mention what appears to be an additional benefit of taking location into account. With the suggestion to consider location and its relation to broader relevant aspects of society, incorporating location helps to broaden the scope of an environmental policy, making it that much more thorough and inclusive.

To summarize, then, I have arrived at the following three method components by expanding on Proctor's proposed methodological guidelines. I have suggested that policy makers: (1) locate an objective component in which to ground differing subjective elements in the debate, (2) take an anthropogenic approach by considering both the instrumental and noninstrumental values of the environmental resource, and (3) take location and all of the relevant relationships into account.

\section{Applying these Components to Bioprospecting}

With the notion of nature as a resource to be communally shared juxtaposed to the notion of nature as a resource to be independently owned as the underlying issue in bioprospecting, I believe that the spe- 

VOLUME 6

cific method components that I have derived from Proctor's methodology can be a helpful tool for those striving to achieve an inclusive global policy on bioprospecting in Third World countries. Unfortunately, due to paper constraints and the complexity of the issue, I will not lay out a detailed policy that might result from applying these methods. Nonetheless, I still believe it is helpful to present a brief example of how policy makers might incorporate these method components. Hence, I will present a generalized explanation of the methods that policy makers can apply, along with an example of how these methods can be applied to a particular bioprospecting case.

The particular case I have in mind is the Australian SmokeBush. ${ }^{5}$ Based on the fact that indigenous Australian tribes had traditionally used this plant for its healing properties to cure numerous illnesses and diseases, the US National Cancer Institute was drawn to investigate the SmokeBush for its possible healing properties with regards to cancer. In the 1960 s, the Western Australian Government granted the NCI a license to harvest this plant for possible cancerfighting properties. Being unable to locate cancerhealing properties, the NCI shelved the plant until the late 1980s when its scientists were able to isolate the active ingredient, 'conocurvan', from the SmokeBush and found that it was effective in fighting the HIV virus. Upon making this discovery, the NCI patented the plant and awarded AMRAD (an Australian pharmaceutical company) a patent to develop the compound 'conocurvan' (Bailey, 1995). ${ }^{6}$ In doing so, indigenous Australian tribes were not recognized or compensated for the role that their traditional knowledge played. ${ }^{7}$ For this reason, I would like to use this case to apply my proposed method components as a means of illustrating how these can be utilized to comprise a more equitable benefit-sharing agreement.

\section{Achieving Moral Pluralism}

In order to incorporate the first guideline (a realist notion of moral pluralism), recall that I have argued that we must take into account both the subjective elements (the diverse perspectives) and the objective element of any given environmental issue. Based on the method component that I derived from Proctor's guideline, we should begin by trying to identify the shared objective aspect of the debate. Although many Third World communities interpret nature as a communal resource, they share the similar objective with corporations in that they also desire to profit from their environmental resources (including their traditional knowledge). ${ }^{8,} 9$

Keeping this in mind, then, it seems possible to achieve a realist notion of moral pluralism regarding bioprospecting. Such a notion would take into account the objective fact that both corporations and communities desire to profit from bioprospecting. At the same time, moral pluralism requires us to also consider the differing aspects with regard to ownership of environmental resources and traditional knowledge. Thus, corporations should recognize that communities currently have a claim to these resources, a recognition that would then allow these communities to have a stake in the profits resulting from bioprospecting. At the same time, these Third World communities should recognize the stake in the profits that corporations are entitled to based on the immense investment of time, money and technology necessary for arriving at a marketable product. Thus, for example, policy makers should consider such questions as: Did the community's use of a certain plant for medicinal purposes completely outside of those eventually gleaned through bioprospecting cause corporations to look at this plant as a possible medicinal source in the first place? If so, then the community's share of the benefits should be proportionately small. If, on the other hand, bioprospectors were able to produce a product that replicated the plant and its exact medicinal purposes for which the community uses it, then the community should receive a much larger share of the profits.

In the case of the Australian SmokeBush, recall that it was initially the indigenous tribes' knowledge of the multiple healing properties of the plant which helped identify it as a likely candidate from among the vastly diverse environmental resources within

\footnotetext{
${ }_{5}^{5}$ Among the well-publicized alleged biopiracy cases, one might recall such popular cases as the neem tree and Basmati rice. In response to the problem of Western corporations utilizing indigenous knowledge and resources without acknowledgement and compensation, India passed the Protection of Plant Varieties and Farmer's Rights Act (2001), which granted individual ownership rights to farmers and breeders, providing a legal basis by which their knowledge and resources must be recognized. Hence, instead of turning to a case in which legislation has been passed to try to protect the rights of indigenous persons, I turn instead to a case (the Australian SmokeBush) in which I believe the legal conclusion regarding benefit sharing was unfair and to which applying the methods I propose would have helped arrive at a more equitable agreement.

6 AMRAD changed its name to Zenyth Therapeutics in December, 2005 (Zenyth Therapeutics, "About Us": "Company History").

${ }^{7}$ Moreover, Australia's Conservation and Land Management Act was amended to include provisions for conservation, which in turn "enabled the denial of the use of smokebush to the aboriginal people who first discovered its therapeutic application (Matur, 23)".

${ }^{8}$ Keep in mind that I am referring to the specific form of bioprospecting in which corporations draw on traditional knowledge and environmental samples in order to arrive at an eventual marketable product. Hence, I am by no means implying that the shared objective element is bioharvesting environmental resources for commercial gain to the extent that doing so negatively impacts the environment.

${ }^{9}$ In fact, in some Third World countries, companies (such as INBio in Costa Rica) have been constructed so as to form business agreements with corporations regarding the profits that bioprospecting might bring (Hamilton, 2004).
} 
Australia. In this way, indigenous knowledge played an important role in the eventual discovery of the healing properties of 'conocurvan' (the active ingredient in the SmokeBush). However, given the immense amount of money and expertise that NCI spent in eventually isolating the active ingredient and identify its useful application, the overall role that indigenous knowledge played was proportionately small. Nonetheless, it is important to note that this knowledge did play an important role and, as a result, achieving moral pluralism calls for compensating Australian indigenous tribes with a small percentage of the benefits derived in AMRAD's marketing of conocurvan. ${ }^{10}$

\section{Incorporating Location and Its Relationships}

In applying the second method component (location) to bioprospecting in Third World countries, it is important to recall that this guideline is not limited to location alone - one must also consider the relationships that extend beyond the particular location. In doing so, there appear to be two important relevant relationships in bioprospecting. First, it is important to note that disagreements over ownership and benefit sharing occur within the larger realm of a market economy. In recognizing this relationship, policy makers should strive for a system of benefit sharing that recognizes both the corporation's input and the extent to which Third World resources and traditional knowledge have added to the development of a marketable product. Second, policy makers should recognize particulars about the relationship between corporations and communities. In addressing this relationship, one quickly notes the disparate power between them. With this in mind, a thorough application of Proctor's second guideline means that policymakers should strive to create an atmosphere in which all parties have equal negotiating power regarding sharing benefits. Of course, this is not to imply that benefits should be shared equally. Instead, equal consideration should be given to the role of each party's input in achieving an eventual marketable product.

In applying this to the SmokeBush example, then, an inclusive bioprospecting policy would incorporate the following three principles. First, in taking location into account, policy makers would be certain to provide for the protection of the SmokeBush, allowing corporations to take samples for research purposes but never to the extent that doing so has a negative impact on this valuable resource. Second, in recognizing the important relationship between Australian indigenous tribes and the SmokeBush, policy makers must note that the traditional knowledge of the healing properties of the SmokeBush is situated within the larger context of centuries of tradition and, thus, reflects an important aspect of cultural identity. Consequently, policy makers must be careful to protect indigenous persons' access to the SmokeBush, being certain not to allow patent law to block their access. And lastly, a recognition of the disparate power between corporations and Third World indigenous communities calls for incorporating protective measures and assurances that the voices of these communities will be both heard and carry equal weight in negotiations. One way in which policy makers could accomplish this would be to appoint a third non-biased party to monitor the negotiations.

\section{Taking an Anthropogenic Approach}

In addition to considering location and incorporating moral pluralism, those working towards an inclusive environmental bioprospecting policy should also be careful to take an anthropogenic approach. Recall that an anthropogenic approach acknowledges human concerns but is not driven by these concerns. Hence, to take an anthropogenic approach to bioprospecting, policy makers should take into account the anticipated benefits to humanity that bioprospecting environmental resources and traditional knowledge in Third World countries may have. With a majority of the world's biodiversity located in these countries, these resources provide the opportunity for discovering cures to many fatal and severely debilitating diseases and illnesses. ${ }^{11}$ However, in weighing these benefits to humanity, policy makers must beware to not take an anthropocentric approach and solely emphasize the benefits to humanity. Instead, as Proctor suggests, they must also take into account nonanthropocentric aspects (those that emphasize the noninstrumental value of the environment). In applying this to bioprospecting, then, policy makers should balance the anticipated benefits to humanity with requirements to preserve the valuable biodiverse region from which corporations and scientists extract samples of environmental resources. Thus, for example, an inclusive policy addressing the Australian Smoke Bush would acknowledge the tremendous benefit to humanity of finding a possible cure for HIV by allowing corporations to have access to the

\footnotetext{
${ }^{10}$ Given the potential millions of dollars of revenue from an HIV drug, a small percentage of the profits still results in substantial earnings for Australian indigenous tribes.

${ }^{11}$ Many of our current medicines are extracted from tropical plants (most of which are located in developing countries). To name a few: vinblastine (extracted from rosy periwinkle; used to treat Hodgkin's disease); vincristine (rosy periwinkle; leukemia); and taxol (Pacific yew; ovarian cancer) (Gepts, 2004, p.1298).
} 

VOLUME 6

SmokeBush, while at the same time being careful not to deplete this valuable resource by allowing corporations to harvest some (but not a damaging amount) of the Smoke Bush in its attempts to find a cure. $^{12}$

\section{Conclusion}

In this paper, I have presented a particular set of method components that I believe policy makers would benefit from using in formulating policies on bioprospecting in Third World countries. To illustrate why this is, I have argued that the underlying issue in the current bioprospecting debates (over ownership and benefits sharing) is differing views of nature. On the one hand, corporations consider nature to be an independently owned resource, while on the other hand, many (though not all) Third World communities consider it to be communally owned. With this in mind, I have argued that policy makers can benefit by applying a set of method components addressed at constructing an inclusive environmental policy (one that is specifically focused on resolving the debate among differing views of nature).

Although this tool can be useful for addressing the underlying issue, it is important to note that it is not a sufficient solution. The issue of bioprospecting is complex, and as a result, requires many tools for arriving at a fair global policy. As such, these methods illustrate only one of these tools, yet one that has been overlooked in the current discourse.

\section{References}

Bailey, B. (1995). New Ideas, Old Laws: Copyright, Patents, Trade Marks and Designs, and How to Avoid Plagiarism. Retrieved September 20, 2006, from Parliament of Australia Parliamentary Library Web site: http://www.aph.gov.au/LIBRARY/pubs/bp/1995-96/96bp12.htm

Benefit Sharing in the National Parks Environmental Impact Statement: What Is Bioprospecting? Retrieved April 12, 2006 from National Park Service United States Department of the Interior Web site: http://www.nature.nps.gov/benefitssharing/whatis.cfm .

Common Policy Guidelines: Convention on Biodiversity (2000, November). Retrieved April 13, 2006 from the Botanic Gardens of Irkutsk State University Web site: http://www.isu.ru/insts /botsad/cbd/cpg99 e.htm .

Gepts, P. (2004). Who owns Biodiversity, and how should the owners be compensated? Plant Physiology, 1295-1307.

Hamilton, R. (2004, April). Bioprospecting, With No Apologies. IDB America Magazine. Retrieved April 12, 2006 from http://www.iadb.org/idbamerica/index.cfm?thisid=2705\&lanid=1

Hardison, P. \& Mauro, F. (2000, October). Traditional Knowledge of Indigenous and Local Communities: International Debate and Policy Initiatives. Ecological Applications, 1263-1269.

Harry, D. \& Kanehe, M. (2005). The BS in Access and Benefit Sharing (ABS): Critical Questions for Indigenous Peoples. In B. Burrows (Ed.), The Catch: Perspectives on Benefit Sharing (pp.81-120). Washington: Edmonds Institute.

Hasan, S. (2002). The Neem Tree, Environment, Culture, and Intellectual Property. Retrieved September 20, 2006 from TED Case Studies Web site: http://www.american.edu/ted/neemtree.htm .

Intellectual Property Issues and Aboriginal Cultural Knowledge (n.d.). Retrieved April 16, 2006 from New South Wales Department of Education and Training Web site: http://www.anu.edu. a u/livingknowledge/html/educators/sic/ip.htm.

Kimbrell, A. (1996, July). Replace Biopiracy with Biodemocracy. Third World Network. Retrieved September 20, 2006 from http://www.ratical.org/coglobalize/ReplaceBPwBD.html

Koopman, J. (2005). Reconciliation of proprietary interests in genetic and knowledge resources: Hurry cautiously! Ecological Economics, 523-541.

Matur, A. (2003, January). Who Owns Traditional Knowledge? Retrieved from Indian Council for Research on International Economic Relationships Web site: http://www.icrier.org/publication/working_papers_archives.html

Megadiverse Countries Join Efforts For Strong International Law on Access and Benefit Sharing (2005, January 25). Retrieved April 12, 2006, from ThirdWorld Network Biosafety Information Service Web site: http://www.twnside.org.sg/title2/service157.htm

Merson, J. (2000). Bio-Prospecting or Bio-Piracy: Intellectual Property Rights and Biodiversity in a Colonial and Postcolonial Context. Osiris, 282-296.

Michael, D. (2000). New Pharmaceutical, Nutraceutical, and Industrial Products: The Potential for Australian Agriculture. Retrieved September 20, 2006, fromAustralian Government/ Rural Industries Research and DevelopmentCorporation Web site: http://www.rirdc.gov.au/reports/Ras/00-173.pdf .

Patten, J., Broun, G. (2004, June). One-Headed SmokeBush Interim Recovery Plan 2004-2009. Retrieved September 20, 2006, from Department of Conservationand Land Management Western Australian Threatened Species andCommunities Unit Web site: http://www.calm.wa.gov.au

Proctor, J. D. (1996). Whose Nature? The Contested Terrain of Ancient Forests. In W. Cronon (Ed.), Uncommon Ground, Rethinking the Human Place in Nature (pp.269-297). New York: W.W. Norton \& Company.

Ramana, A. \& Smale, M. (2004). Rights and Access to Plant Genetic Resources Under India's New Law. Development Policy Review, 423-442.

\footnotetext{
${ }^{12}$ Of course, as previously noted, the protection of the SmokeBush is covered by Australia's Conservation and Land Management Act.
} 
Shiva, V. (2000). North-South Conflicts in Intellectual Property Rights. Peace Review, 501-508.

Siebenhuner, B., Dedeurwaerdere, T. \& Brousseau, E. (2005). Introduction and overview to the special issue on biodiversity conservation, access and benefitsharing and traditional knowledge. Ecological Economics, 439-444.

The New Piracy: How West 'Steals' Africa's Plants (2006, August 28). Kenya London News. Retrieved from http://www.kenyanewsnetwork.com/artman/publish/article_835.shtml .

Weston, K. (2003, September). The Impact of TRIPs on Agricultural Economies in the Developing World. E LAW. Retrieved April 12, 2006, from http://www.murdoch.edu.au/elaw/issues/v10n3/weston103_text.html .

Whose Rules of the Game? Bioprospecting and Drug Research in Developing Countries (2006, April 19). Retrieved May 16, 2006, from United NationsUniversity Web site: http://www.ony.unu.edu/seminars/2005/bioprospecting19april05.htm

Zenyth Therapeutics (n.d.). Retrieved September 23, 2006, from http://www.zenyth.com.au .

Zerbe, N. (2005). Biodiversity, ownership, and indigenous knowledge: Exploring legal Frameworks for community, farmers, and intellectual property rights in Africa. Ecological Economics, 493-506.

\section{About the Author}

Ms. Pamela J. Lomelino

My academic interests include Bioethics, Feminist Philosophy, Environmental Philosophy, Ethical Theory and Applied Ethics. I am currently working on my dissertation, "An Ethical Analysis of Creating Beings for Human Use", in which I focus on four controversial case studies involving creating beings for human benefit (creating human embryos for stem cell research; creating inter-species stem cell chimeras for research; creating geneticaly modified animals for human organ harvesting; and creating children for such things as bone marrow transplants for sibblings with immune system diseases). In addition, I am currently working on an ethical analysis of the philosophical and policy issues that arise from the corporate practice of Bioprospecting, as well as writing on a Feminist approach to reclaiming tools of oppression as a means of empowerment. All of the issues on which I focus have the common thread of dealing with systems of oppression as expressed (and reinforced) in the field of Medicine, Medical Technology, and global capitalist endeavors. 



\section{THE INTERNATIONAL JOURNAL OF DIVERSITY IN ORGANISATIONS, COMMUNITIES AND NATIONS}

\section{EDITORS}

Mary Kalantzis, University of Illinois, Urbana-Champaign, USA.

Paul James, RMIT University, Australia

\section{EDITORIAL ADVISORY BOARD}

Ien Ang, University of Western Sydney, Australia.

Samuel Aroni, University of California, Los Angeles, USA.

Duane Champagne, University of California, Los Angeles, USA.

Guosheng Y. Chen, RMIT University, Melbourne, Australia.

Jock Collins, University of Technology, Sydney, Australia.

Bill Cope, University of Illinois, Urbana-Champaign, USA.

Heather Marion D'Cruz, Deakin University, Geelong, Australia.

James Early, Smithsonian Institution, Washington, DC, USA.

Denise Egéa-Kuehne, Louisiana State University, Baton Rouge, USA.

Amareswar Galla, Australian National University, Canberra, Australia.

Barry Gills, University of Newcastle, UK.

Margot Hovey, Curriculum Designer and Writer, Toronto and Montréal, Canada.

Jackie Huggins, University of Queensland, Australia.

Andrew Jakubowicz, University of Technology, Sydney, Australia.

Ha Jingxiong, Central University of Nationalities, Beijing, China.

Peter McLaren, University of California, Los Angeles, USA.

Joe Melcher, Xavier University of Louisiana, New Orleans, USA.

Greg Meyjes, Solidaris Intercultural Services L.L.C, Falls Church, VA, USA.

Walter Mignolo, Duke University, USA.

Brendan O'Leary, University of Pennsylvania, USA.

Aihwa Ong, University of California, Berkeley, USA.

Peter Phipps, RMIT University, Melbourne, Australia.

Ronald Prins, Managing Director, Bos en Lommer Neighbourhood Council, The Netherlands.

Peter Sellars, Theatre, Opera and Film Director.

Michael Shapiro, University of Hawai'i, USA.

David S. Silverman, Valley City State University, North Dakota, USA.

Martijn F.E. Stegge, Diversity Platform, City of Amsterdam, The Netherlands.

Geoff Stokes, Institute for Citizenship and Globalisation, Deakin University, Melbourne, Australia.

Terry Threadgold, Cardiff University, Wales, UK.

Mililani Trask, Indigenous Expert to the Permanent Forum on Indigenous Issues for the Economic Council of the UN Assembly, Hawai'i, USA.

Marij Urlings, Dean, School of Health Inholland University, Amsterdam-Diemen, The Netherlands.

Joanna van Antwerpen, Director, Research and Statistics, City of Amsterdam, The Netherlands.

Grethe van Geffen, Seba Cultuurmanagement, Amsterdam, The Netherlands.

Rob Walker, Keele University, UK.

Ning Wang, Tsinghua University, Beijing, China.

Owens Wiwa, African Environmental and Human Development Agency, Toronto, Canada.

Please visit the Journal website at http://www.Diversity-Journal.com for further information: ABOUT the Journal including Scope and Concerns, Editors, Advisory Board, Associate Editors and Journal Profile

FOR AUTHORS including Publishing Policy, Submission Guidelines, Peer Review Process and Publishing Agreement

\section{SUBSCRIPTIONS}

The Journal offers individual and institutional subscriptions. For further information please visit http://ijd.cgpublisher.com/subscriptions.html. Inquiries can be directed to subscriptions@commongroundpublishing.com

INQUIRIES

Email: cg-support@commongroundpublishing.com 